\title{
A study on Disaster Management and Related Legislation in Korea
}

\author{
Han-bual Kim ${ }^{1}$, Hong-sic Yun $^{2}$ and Min-kyo Youm ${ }^{3}$
}

\begin{abstract}
Nowadays, all nations in the world face with the hazards triggered by the disasters. There have been various disasters in recent years. Such as climate accidents and the disasters like earthquakes, typhoons, floods, complexity caused by urbanization. In Korea, the disaster management system and law have been blamed for years. Since there is "Pass the buck" practices in dividing the responsibility and the laws in Korea has some ambiguous points. In this regards, I want to scrutinize the laws and disaster management system in Korea so far, and want to research other countries system. There is some points we can emulate and improve from the America and Japan's system.
\end{abstract}

Keywords-Disaster, Disaster management system, Law. Precedent of other countries.

\section{INTRODUCTION}

Nowadays, climate accidents and the disasters like earthquakes, typhoons, floods, complexity caused by urbanization have become close to us. However, it is difficult to anticipate and response to all events like that. In the real disaster situation, each nation considers countermeasure to manage the calamity and establishes management system for more efficient response.

Korea is not an exception. Including the Sewol-ho sinking accident, sink-hole accidents in Seoul, the collapse of ventilation system in Pan-gyo, there were severe disasters in Korea so far. And they brought damages of human life and property loss. Nevertheless, there were lots of pointed out shortages in processing the disasters in Korea. In addition, the people in Korea also distrust the government. This study starts at the question, "What should we do for making safe Korea?" I will review the current disaster management system and Law, so far in Korea. Furthermore, I plan to introduce the good sample of Law in advanced country. We can compare those Laws and can benchmarking it, fitting for our circumstance. It can give us the guidance to improvements in Law.

\section{BODY}

\section{A. Disaster Management System and its law weakness in} Korea

According to the Construction 34-6 provision, "The Nation

\footnotetext{
${ }^{1}$ The master's course, Interdisciplinary Program in Crisis, Disaster and Risk Management, Sungkunkwan University, Suwon, republic of Korea

${ }^{2}$ School of Civil and Architecture Engineering, Sungkyunkwan University, Suwon, 440-746, republic of Korea

${ }^{3}$ The Doctor's course, Interdisciplinary Program in Crisis, Disaster and Risk Management, Sungkunkwan University, Suwon, republic of Korea
}

should prevent the disasters and should protect the citizens from the hazards." To realize this spirits, "Disaster and Safety supervision Law." Legislated as a fundamental Law. "Civil defense Law." also enacted for traditional security object. However, in real situations, safety supervision legislates are enacted as 80 individual laws in 13 different departments.

Dual separation like this has some weakness. Since governmental organizations with other organizations has little connection in regards of safety individual laws and one group cannot recognize the other's regulations. In this modern society, most of disasters outbreak not just one reason, but complex causes. In this perspective, when catastrophe happens, the direct department is decided by the occurrence cause and disaster type. In Korea, it decided by the type of disaster. In this case, department responses to each legislates. It makes prolong time and difficult to share the responsibility by their ambiguousness. As a result, it aggravates the "Pass the buck" responsibility. When disaster happens, the command system cannot operate in perfect order, it makes the field confuse. Thus we need close connection between each administrations and organic work responsibility.

Laws Related to Disaster in Korea

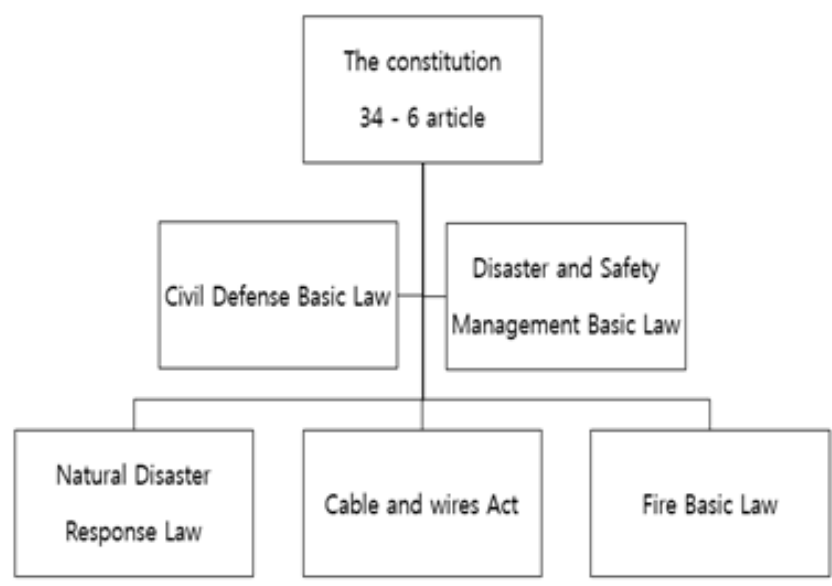

Fig. 1: Laws Related to Disaster in Korea

\section{B. Precedent of United States of America}

We can find improvement guidance in foreign management system and laws. First, in United States of America, "the Stanford Law" legislated in 1988, and it became fundamental management law. It regulates the responsibility clearly between central government and local government. It is worthy of the "Inclusive management system." 


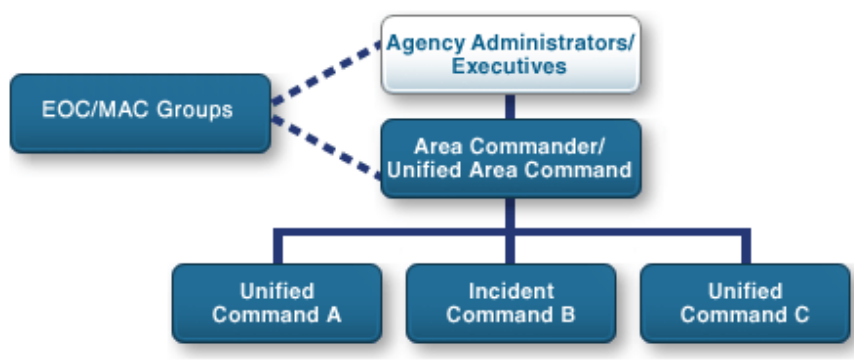

Fig. 2: Command System in the United States of America

Based on Stanford law, they manage the disaster not by the type, but by in the conception of consolidation. In addition, they have federal response plan and federal coordination system. It makes field commander more professional. Above picture shows the Command system in America. Following this picture, the Agency Administrators can be explained by the commander.

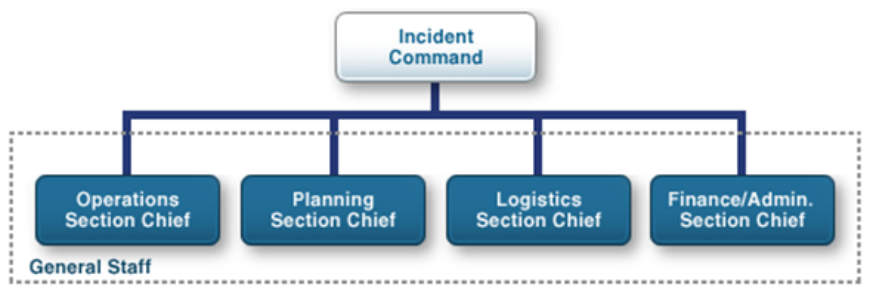

Fig. 3: Incident Command System in the United States of America

This data shows the unified incident command system in US. Incident command system consists of 4 parts, Operations Section Chief, Planning Section Chief, Logistics Section Chief, Finance/Admin Section Chief. Those extinct divisions can help to cope with the disaster easily. Because, each department has its preparedness.

In addition, there is Federal coordination system in US. It means in case of catastrophe, the coordinator acts as a president's agency and operates response and command. It can help to reduce the delay of Administration. For perfect order system, we need to emulate this system.

\section{Precedent of Japan}

Last example is Japan. In Japan, disaster countermeasure enacted in 1961 as a fundamental law with other related legislations. The disaster countermeasure laws deal with the protection object, the subject of duty, the system of management and the clearance of obligation, administration plan. The lesson of Japan's law is that it operates the management system by functions. First, the cabinet makes the central government operates by colligated concept. Meanwhile autonomous community establish the plan for preventing disasters in large scale. Firefighters, police officers and the self-defense forces will perform key role in field. Comparing with our system which operates by type, the Japan's system will be more effective and professional in response, cause it classified the disasters by functions.

\section{CONCLUSION}

This All nations face with the hazards of disasters and they prepare for that. Nevertheless, there are limits in effective preparations. At this point of time, scrutinizing the law, institutions and policy of disaster management can give us possibility to coordinate the current system and to improve the laws.

There are two ways to improve our system in the regards of law. First, we need to clarify the subject of the responsibility and make inclusive system like America's Stanford law. It will reduce our "pass the buck" practices. Second, government and other related departments will be closely connected and classified by the features like Japan's law. Most of disasters need essential features such as situation management, medical prevention, emergency communications, environmental improvements. Therefore, before the disaster time, those features is classified obviously and trained repeatedly.

If we consider and improve at these points, we can make safe Korea by the developed management system and law.

\section{ACKNOWLEDGMENT}

This work is financially supported by minister of public safety and security as $<\mathrm{BK} 21$ Plus creative technology of crisis, disaster and risk management $>$.

\section{REFERENCES}

[1] In Sool Yu, "Disaster Planning in Korea", Department of Emergency Medicine, Chungnam University School of Medicine, Daejeon, Korea, 2015

[2] McLoughlin D, "A framework for integrated emergency management. Public”, 1985.

[3] Cho SJ. Study on law and regime relating to the disaster and safety management. KRCEM, 2010

[4] Chung Ryu. Disaster management. 2nd ed. Seoul. Hansung Culture, 2005

[5] Ryu SL, Namkung ST. Analyze the act on disaster and safety management in Korea. Korean Review of Crisis \& emergency Management, 2011 